\title{
La Integración del ahorro privado a la producción consensuada
}

\section{The integration of private savings to consensual production}

\author{
René Patricio Palomeque Cantos ${ }^{1 *}$ y Jhon Genaro Molina Hugo ${ }^{1}$ \\ ${ }^{1}$ Universidad Católica de Cuenca \\ *jgmolinah@ucacue.edu.ec
}

DOI: https://doi.org/10.26871/killkana_social.v2i3.339

\begin{abstract}
Resumen
Un objetivo básico de la sociedad es la lucha contra la desigualdad social, la pobreza y la ineficiente utilización de recursos, aspectos que mantienen el subdesarrollo, como es una problemática constante en nuestras sociedades. En las últimas décadas los países y organizaciones del desarrollo, han desplegado esfuerzos para reducir la pobreza, sin embargo, los resultados han sido adversos, más bien, se ha incrementado, sobre todo, en países de América Latina, donde la falta de empleo, ha sometido a la población a la carencia y pobreza. El objetivo general, consiste en formular procesos productivos eficientes, que reviertan la condición de pobreza, mediante la potenciación de la capacidad que dispone cada sociedad, conforme acuerdos productivos y colaborativos con métodos de entendimiento de intereses y propósitos comunes, que no son altruismos ni egoísmos, sino un ganar, ganar, con acuerdos atípicos de mutuo beneficio. La metodología es la de consultar fuentes primarias y secundarias, sobre integración de los actores económicos, planteando una propuesta que engrane voluntades y decisiones, recursos y procesos, donde, los sectores socioeconómicos, concierten alianzas productivas, como sinergia social, que activen el potencial productivo nacional.Se obtendrán resultados socioeconómicos exitosos, cuyos impactos se apreciarán en el nuevo concepto de producir y participar, conforme integración de las fuerzas productivas mediante alianzas público privadas reales y denodadas, que permitirá disponer más inversión nacional y externa. Se lograrán conclusiones relevantes sobre la eficiente forma de producir e integrar más personas a la riqueza, aspectos que conducirán al desarrollo.
\end{abstract}

Palabras clave: acuerdos productivos, alianzas, empresas consensuadas.

\begin{abstract}
A basic objective of society is the fight against social inequality, poverty and the inefficient use of resources, aspects that maintain underdevelopment, as it is a constant problem in our societies. In the last decades the countries and organizations of the development, have deployed efforts to reduce the poverty, nevertheless, the results have been adverse, rather, it has increased, mainly, in countries of Latin America, where the lack of employment, it has subjected the population to poverty and poverty. The general objective is to formulate efficient productive processes that revert the condition of poverty, through the empowerment of each society, according to productive and collaborative agreements with methods of understanding of common interests and purposes, which are not altruism or selfishness, but a win, win, with atypical agreements of mutual benefit. The methodology is to consult primary and secondary sources on the integration of economic actors, proposing a proposal that links wills and decisions, resources and processes, where socio-economic sectors, enter into productive alliances, such as social synergy, that activate the productive potential national. Successful socioeconomic results will be obtained, whose impacts will be appreciated in the new concept of producing and participating, in accordance with the integration of the productive forces through real and daring public-private partnerships, which will allow more national and external investment. Relevant conclusions will be reached on the efficient way of producing and integrating more people to wealth, aspects that will lead to development.
\end{abstract}

Key words: productive agreements, alliances, consensual companies.

\section{Introducción}

Todas las sociedades buscan orientar resultados para asignar eficientemente recursos que busquen su desarrollo integral en forma permanente, existen recursos en cantidades importantes tanto en el sector privado como en el sector público, que, por razones de intereses, o conceptos políticos, no ha sido posible, generalmente, aprovechar de forma integral u óptima estas fuentes de riqueza de estos dos sectores.

En el mundo han existido experiencias de alianzas público privadas (APP) que han buscado encontrar recursos para resolver grandes necesidades sociales, así, desde 1950 asoman tanto en España (Molina, 2016) como en Francia (Francois, 2016), aunque luego en el Reino Unido, el cual desarrolla provisión de servicios públicos de largo plazo 
con el criterio de pagos diferidos por disponibilidad y uso, aspecto para que otros países como Japón, Rusia, Australia, Canadá, etc. Tomaran iniciativas en este aspecto, que son referencias sobre iniciativas de financiamiento en alianzas público privadas. En el continente americano, en México, se avizora esta modalidad al final de la década de los ochenta y comienzos de los noventa, con el objeto de concesionar vías de comunicación.

En 1991 Chile aprueba su Ley de Concesiones (infraestructurales), constituyéndose en referencia para otros países mediante el uso de mercado de capitales (uso de bonos sobre fondos pensionales, seguros de vida y peajes) (Vieitez y col., 2016). En Ecuador el desarrollo de esta modalidad, ha sido casi insignificante, no obstante, desde el 18 de diciembre de 2015, el país pone en vigencia su Ley Orgánica de Incentivos para las Asociaciones Público Privadas y la Inversión Extranjera (LOAIAPP, 2015), que busca establecer incentivos de financiamiento para proyectos con modo APP.

Existe observancia para esta temática en el ordenamiento jurídico, así, la Constitución de la República (Asamblea Nacional, 2015b) en el artículo 425, y en especial en los artículos que van desde el 313 hasta el 316, el Código Orgánico de la Producción (COPCI) (Asamblea Nacional, 2015a); la Ley de Compañías (Asamblea Nacional, 2014), artículo 308; la Ley Orgánica de Empresas Públicas (LOEP) (Asamblea Nacional, 2015c), referente a los artículos desde el 34 al 36; el Código Orgánico de Organización Territorial, Autonomía y Descentralización (COOTAT) (Asamblea Nacional, 2010); y, Ley de Modernización del Estado, Privatización y Prestación de Servicios Públicos (Congreso Nacional, 1993). A este cuerpo legal se suman varios reglamentos.

A pesar de esta variada normativa, se puede afirmar que no tiene una sólida certidumbre jurídica para atraer la inversión nacional y extranjera en este tipo de alianzas sustentables, ya que, enfatiza más en responsabilidades operativas y obligaciones financieras, y no constituyen una verdadera base que trace el camino y atraiga con facilidad y seguridad los recursos privados, como fuente de financiamiento permanente y barata para resolver los problemas críticos que en esta materia tiene el país, si sólo se remarca el artículo 15 de la LOIAPP, que señala que exime de responsabilidad jurídica al Estado y su normativa ante discrepancias con los contratos de gestión aprobados, siendo un obstáculo limitante.

Se podría considerar al respecto que, existe una supremacía del Estado sobre la participación privada, aspecto que le coloca al sector privado en una desventaja competitiva, puesto que éste no tiene mayores opciones de ganar discrepancias al Estado, en caso de controversias, como están las cosas, a pesar de que la Constitución de la República prevé como principios rectores la seguridad y certeza jurídica. Asoma como evidente, entonces, que no existe un marco jurídico claro en los procedimientos de concursos públicos de la LOIAPP para escoger el gestor privado. (Baldeón Barriga, 2016)

El Decreto Ejecutivo 582 (Presidencia de la República, 2015), que afina detalles de este proceso, resulta lento y cargante, por el que la aprobación de un proyecto APP demora mucho y es complejo, más aún, por cuanto un gestor privado, no tiene posibilidad de recaudar por su trabajo en la etapa de preparación y presentación de la propuesta. Dicho en otras palabras, todos estos aspectos generan incertidumbre jurídica, por lo tanto, inseguridad para el inversionista privado, lo cual, per se, ya es una gran barrera para captar el tan ansiado, como necesario ahorro privado. Por el antecedente, y debido a la situación económica en la que se encuentra el Ecuador, estamos obligados los ciudadanos a presentar alternativas de gestión productiva que permitan tomar en forma complementaria y bien afinados los recursos de ambos sectores, que permitan resolver los problemas que mantienen la pobreza en el país y empantanan el desarrollo, ya que, se estima que entre el 33 y $40 \%$ apenas, se considera existe, como probable éxito en un proyecto APP en el Ecuador (Baldeon Barriga, María, 2016).

El problema a tratar es que, este país es rezagado, que adolece de males seculares como la pobreza, la falta de fuentes de empleo, inestabilidades recurrentes, escaso crecimiento y, por ende, falto de condiciones para el desarro1lo, de ahí que, es necesario establecer cuáles son las características que determinan los limitantes de su crecimiento y desarrollo. En la última década, no tuvo mayores problemas cuando las condiciones externas e internas del país le fueron favorables, aunque con escaza inversión privada, sobre todo externa, sin embargo, la compleja situación mundial, incluida la desaceleración económica de China, la abrupta caída del precio del petróleo, la revalorización del dólar, la contracción y encarecimiento del crédito bancario, el encarecimiento de las exportaciones, el abaratamiento de las importaciones, la estructura estatal obesa, el incremento del desempleo, el terremoto de la costa norte ecuatoriana, y el sobreendeudamiento del país, e incluso su posición política, afectaron de forma sensible a la economía nacional, aspecto que obligó a la búsqueda de nuevas fuentes de financiamiento duras para revertir la crítica situación en la que se aún se encuentra el país.

Por ende, el objetivo general de este trabajo busca formular procesos productivos sociales eficientes, que reviertan la condición de pobreza, mediante la potenciación de la capacidad que dispone cada sociedad, conforme acuerdos productivos y colaborativos con métodos de entendimiento de intereses y propósitos comunes, que no son altruismos ni egoísmos, sino un ganar, ganar, con acuerdos atípicos de mutuo beneficio. Para lograr este cometido se requiere encontrar un mecanismo que libere de incertidumbre y llene de confianza al ahorrista privado, de tal modo que, decida invertir en variantes de APP con liderazgo público. Para conocer el criterio del inversionista privado, se realizó una investigación mediante encuestas y entrevistas a un número 
determinado de empresarios, en la provincia del Azuay, en especial en Cuenca, utilizando la fórmula pertinente para establecer una muestra confiable. Se consideran variables clave para este propósito: el liderazgo productivo del Estado; $\mathrm{y}$, la confianza y la certidumbre del empresario privado, para juntos emprender proyectos concertados. Es importante recalcar que la investigación tropieza con limitaciones o impedimentos como son la falta de interés y apertura por parte del empresario para contestar peguntas que abordan este tema. El estudio marca un antes y un después, en el entendimiento de converger ambos sectores en un mutuo beneficio, sin exclusiones, sino más bien inclusiones, lo cual formula una tesis de beneficio integral.

\subsection{Ciertas referencias coyunturales del Ecuador}

El Ecuador ha experimentado un tendencial déficit del ahorro que se destina a la inversión, sobre todo desde 2009, aspecto que obligó al gobierno a la búsqueda permanente de recursos, ya sean internos (IESS, BCE, etc.) o externos (Créditos de gobiernos, preventa de petróleo, etc.), esto, debido al incremento del gasto público en el país. No obstante, ha sido el sector privado el que ha aportado en mejor manera este recurso, ya que sus saldos en esta actividad han sido positivos y crecientes.

En una economía abierta, el equilibrio se manifiesta cuando su ahorro total es igual a su inversión total, si el ahorro es inferior a la inversión esperada, existe déficit, aspecto que obliga a demandar recursos exteriores, generalmente, vía endeudamiento, esta situación se ha dado en Ecuador de forma recurrente y progresiva, en cambio, el sector privado ha mantenido este saldo de forma efectiva, lo cual evidencia que existen recursos acumulados disponibles para ser invertidos, y que no siempre tienen este destino. Se colige, por tanto, que la salida de las divisas se estimula por esta situación deficitaria que provoca el sector público, es decir, mientras sector privado genera dólares, el gobierno los hace escapar mediante el pago de deuda (Cámara de Comercio de Guayaquil, 2018a)

El resultado ahorro-inversión del sector público en los años 2015 al 2017 fue de USD 3.043, USD 7.937 y USD 6.076 millones, respectivamente, mientras que, en el mismo período el Estado escapó USD - 5.124, USD 6.495 millones y USD - 6.332 millones, en el mismo orden (Tabla 1.), generándose una tendencia de una brecha entre el ahorro público y privado que se va ampliando desde 2007. Así, en este año, el ahorro privado en relación al PIB era del $18 \%$ aproximadamente, en tanto que, el ahorro público fue del $8 \%$ en relación al PIB, o sea una brecha de 10 puntos del PIB entre estos dos sectores. Para 2017 el ahorro privado representó el $20 \%$ del PIB, en tanto que, el ahorro público fue solo del $5 \%$, es decir, la brecha aumentó en 15 puntos en relación al PIB (Cámara de Comercio de Guayaquil, 2018b).
Tabla 1 Evolución Ahorro - Inversión

\begin{tabular}{|c|c|c|}
\hline Año & $\begin{array}{c}\text { Sector } \\
\text { Privado }\end{array}$ & $\begin{array}{c}\text { Sector } \\
\text { Público }\end{array}$ \\
\hline 2015 & 3.043 & -5.124 \\
\hline 2016 & 7.937 & -6.495 \\
\hline 2017 & 6.076 & -6.332 \\
\hline En millones USD
\end{tabular}

Fuente: Departamento de investigación de la Cámara de Comercio de Guayaquil, Argumentos de Posición Estratégica No 23.

Elaboración: Autores

Por otra parte, el desempleo en Ecuador ha sido una constante sensible, ya que éste expresa uno de los aforos de la economía para generar riqueza en base a su capacidad productiva, por lo que, en los últimos 4 años, el país ha experimentado tasas de desempleo que van desde el 7,4\% (inicios de 2016), hasta el 5,4\% (finales de 2017), como sustenta la Figura 1, aspecto que expresa, por una parte, la falta de capacidad productora y la inestabilidad económica, y por otra, la escasa inversión productiva en la economía.

Figura 1. Ecuador - Tasa de desempleo

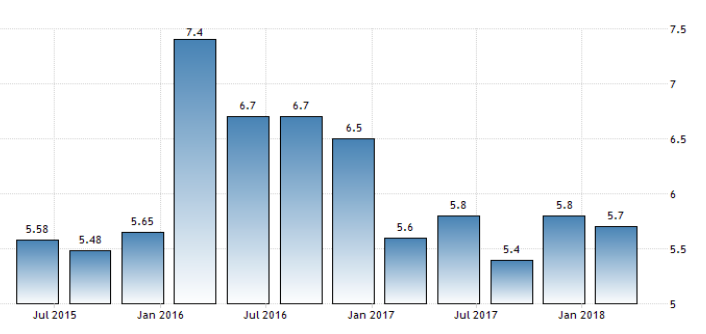

Fuente y elaboración: www.tradingeconomics.com, estadísticas para Ecuador. Obtenido de:

https://es.tradingeconomics.com/ecuador/unemployment-rate

El ministro de Finanzas de Ecuador, Richard Martínez, informó que la Deuda Pública del país asciende a USD 58.980 millones, monto que equivale al $58 \%$ del Producto Interno Bruto, donde constan rubros tanto de deuda externa como de interna agregadas y otras cuentas como deuda flotante, preventas y otras obligaciones, no obstante, de que la normativa en el país señala que el, límite máximo de endeudamiento es del $40 \%$ del PIB, conforme lo establece el Código de Planificación y Finanzas Públicas (Coplafip) (El Comercio, 2018), aspecto que per se, demuestra la excesiva carga de deuda del país, que no tienen una consistente capacidad productiva y no sabe aprovechar bien sus recursos.

Conforme al Repositorio de la CEPAL (CEPAL, 2016), el sector público del país, en 2015 de endeudó en el exterior de mayor forma, con el objeto de abultado financiar el déficit, conforme colocación de bonos y créditos bilaterales y multilaterales por monto de USD 1.500 millones, siendo China el primordial acreedor, siendo el $27,1 \%$ de la deuda pública externa, con 3 puntos menos que en 2014 , considerando que el financiamiento con fuentes internas constan los certificados de tesorería, la disminución de 
depósitos del sector público (no financiero) en el Banco Central, el incremento de retardos en la deuda flotante, reducción de deuda doméstica, ya que, las amortizaciones fueron mayores que los desembolsos, por ello, la deuda pública aumentó al 32,5\% del PIB, de la cual, el 20,1\% correspondió a la deuda externa, en tanto que, la interna fue del $12,4 \%$.

El gobierno central precedente, tomó medidas para disponer recursos necesarios para enfrentar la devastación del terremoto en las costas de Manabí y Esmeraldas, creó la Ley Solidaria de Corresponsabilidad Ciudadana, estableció exoneraciones de impuestos para damnificados y donaciones, como también sobretasas a varios impuestos, como el IVA del 12 al $14 \%$, contribución de un día de sueldo según ingresos; $3 \%$ de las utilidades, un $0,9 \%$ de contribución patrimonial a patrimonios de 1 millón o más, venta de activos del Estado, entre otras puntualidades, con lo cual se recaudó alrededor de 1.000 millones de dólares. A este proceso recolector de ahorro nacional, se sumaron líneas de crédito de organismos multilaterales (CAF, BID, BM y FMI), por USD 1.060 millones, asoma el déficit de las balanzas por cuenta corriente, principalmente, por la disminución de remesas y la depreciación del euro, el pago de bonos vencidos, sumados a esto la reapreciación del dólar, la baja del precio del petróleo, son, los principales aspectos que minaron la estabilidad fiscal y redujeron el disponible y el ahorro (CEPAL, 2016).

Un referente práctico para atraer el ahorro privado externo para la inversión, es el concepto de Riesgo País - EMBI (Emerging Markets Bonds Index) (Invenómica, 2018), y es un índice principal del JP Morgan Chase, el que expresa, que por cada 100 puntos, un país pagará 1 punto más por encima del rendimiento de los bonos libres de riesgo (Treasury Bills), por lo que, determina un nivel de confianza para inversionistas en países de América Latina, conforme a esto, Ecuador ha obtenido 1.592 puntos en 2016; 607 en 2017; y, 450 en 2018 (La República, 2018) (todos a inicios de cada año), Perú: 276, 151 y 123, respectivamente; Colombia: 364, 301 y 234, en la misma disposición; y, Chile: 283, 143 y 107, en igual consideración. Esto significa que, si se compara entre estos países referentes, el indicador sitúa al Ecuador en el lugar inferior, aspecto que explica, entre otros reparos, la escasa inversión externa e interna que sustenta el país en estos años.

$\mathrm{Al}$ analizar el Índice sobre la percepción de corrupción de América Latina, que determina una escala, desde una alta corrupción a muy transparente, que va de cero a cien, en base a ciertos factores, de un panel de 180 países, en 2017, la ONG alemana Transparencia Internacional (TI) (France 24, 2018), ubica al Ecuador con una calificación de 31 puntos, y puesto 120, cuya mejor referencia en América es Canadá, puesto 8, tiene 82 puntos, y la peor Venezuela en el puesto 169. El caso sonado de corrupción en los países de nuestra región de la empresa brasileña Odebrecht en 2018, ha denotado penosas prácticas, por la forma de financiar obras públicas motivadas por sobornos privados, donde los denunciantes han experimentado ataques, por el hecho de denunciar (... ). Para 2018 la TI, ubica al país con 32 puntos y puesto 117 (Diario Las Américas, 2018), mientras que los vecinos Colombia, 27 puntos, lugar 96; Perú, puesto 37 y 101 puntos; y Chile 26, con 67 puntos, siendo, nuevamente, Ecuador el inferior entre estos comparados.

Un valioso referente que expresa la imagen país sobre la facilidad de hacer negocios, es el Índice DB (Doing Business) del Banco Mundial (Banco Mundial, 2018), que refleja las regulaciones para facilitar negocios en un país, es otro indicador que expresa la atracción de inversión extranjera hacia un país, en el cual Ecuador, en este año, se sitúa en el puesto 118 entre 190 países evaluados, de conformidad al ranking DTF (Distance To Frontier), que precisa el desempeño observado en cada uno de los indicadores que forman el DB, en el cual, el país sustenta 57,83 puntos DTF, score que permite comparar con las mismas economías, así: Chile, puesto 55 DB, con 71,22 puntos DTF; Perú, puesto 58 DB, con 69,45 puntos DTF; y, Colombia, puesto 59 DB, con 69,41 puntos DTF, parámetros que ubican al país, de nuevo, en una incómoda desventaja ante el potencial inversionista.

Por consiguiente, los variados indicadores ilustrados, configuran, con mucha aproximación, las primeras razones sustentables por las que el Ecuador ha sido considerado como un país de poca atracción para canalizar recursos de ahorro-inversión. El resto de razones se alinean a la posición política y al mantenimiento atávico de una forma de producir desarticulada, ineficiente y rígida, que no innova ni se desarrolla.

\section{Marco teórico o antecedentes}

La tradición teórica considera una marcada distinción entre la administración pública y la sociedad civil, conocida como la dicotomía público-privada. Es curioso el planteamiento del alemán Max Weber y el norteamericano Robert Dahl, que afirman la existencia de un Estado jerárquico, donde debe existir una necesaria diferencia entre los gobernados y el gobierno, donde debe existir de forma clara la distinción de lo privado y lo público, donde el Estado gobierna a los civiles, pero no requiere para gobernar de su colaboración (Robalino Orellana, 2011).

El mundo político se ha visto confrontado en los siglos XX y XXI con teorías aparentemente irreconciliables: Socialismo vs liberalismo y/o estatismo vs iniciativa privada, con sus neo-vertientes, tanto así que, los enfoques teóricos sobre estas posturas se han vuelto aparentemente incompatibles y, es más, antagónicos en la mayoría de análisis teóricos al respecto. Una suerte de varas, tanto para el manejo público como parea el privado, en su orden. Una tercera corriente ideológica, escaza y frágil, asoma como conciliadora e incluyente entre estas posturas, que propone tomar lo mejor de cada uno, o identificar puntos en común para conciliar su mutuo beneficio, caso de las APP.

El socialismo y el estatismo han marcado dogmas como que el Estado altruista resuelve todos los diferendos 
sociales, eliminando los intereses privados sobre el ser social, en cambio, el neoliberalismo o gestión privada, propone el egoísmo consustancial al ser humano como base del desarrollo, privilegiando la propiedad privada y la libertad de mercado, posturas en teoría irreconciliables, aparentemente, pero que, en la realidad advierten elementos en común, que conforme este estudio, se pueden conjugar, o complementar, es más, volverse más eficientes y dimensionados, conforme alcancen acuerdos concertados de intereses, donde cada parte mantiene sus beneficios, su integridad, gana la sociedad en resultados ya que tienden a reducir el desempleo, la pobreza, mejoran la tecnología, por ende la productividad y la competitividad, aumentan la inclusión social y el crecimiento económico, cambiando roles ortodoxos de los actores de cada uno de estos sectores. Su nombre: Producción consensuada.

La investigación siguió la referencia teórica de los planteamientos sobre "Macroeconomía con aplicaciones a Latinoamérica", de Paul Samuelson y William Nordhaus (Samuelson, W. y Nordhaus, 2010), como primer referente general; además de ello, las bases teóricas de la obra "Economía Internacional, Teoría y Política", de Paul R. Krugman (Krugman Obstfeld y Mélitz, 2016) y otros. Adicionalmente, esta investigación se relacionó con la obra "La construcción Social de las teorías del desarrollo", de Isaac Enríquez Pérez (Enriquez, 2009), "Política Económica" de Lucas Pacheco (Pacheco, 2009), que son las teorías y autores más referentes que han aportado valiosos criterios y guía sobre el enfoque del presente trabajo.

\section{Metodología}

La metodología que se utilizó para realizar esta propuesta consiste en conocer los aspectos más sobresalientes que caracterizan la situación del ahorro en la economía nacional para determinar un punto de partida, bajo el criterio de un enfoque basado en resúmenes. Se expone luego los desafíos y propuestas que se quieren alcanzar con este planteamiento, es decir, un antes y un después que permita establecer la viabilidad de lo propuesto, en donde las partes intervinientes mantengan un ganar-ganar. Para el efecto se utilizó un breve diagnóstico coyuntural, conforme recolección de información, con uso de fórmulas para tomar muestras y la aplicación de encuestas, que generó la línea base situacional; luego, se investigó conforme el método teórico inductivo-deductivo, que generó la idea propuesta para la solución al problema, que es la falta de ahorro transferido a la inversión.

Se ha considerado el universo de las Micro, Pequeñas y Medianas empresas (Mipymes) de la provincia del Azuay, como referente para este trabajo, de las cuales, una vez aplicada la fórmula de cálculo respectiva y el diseño de la información a aplicarse, sobre una población de 50.670 Mipymes (Inteligencia Productiva, 2018), al año 2016, (un $5 \%$ del total del país), de las cuales 46.124 son microempresas, 3.841 pequeñas empresas y 705 medianas empresas, arrojó una muestra de 84 Mipymes, debidamente segmentadas, a cuyos propietarios se les efectuó la consulta, respetando la magnitud de sus segmentos. El proceso generó datos reales y globales, confiables estadísticamente. La recolección de datos primarios se realizó mediante la aplicación de encuestas y entrevistas focales, que se tabularon debidamente, con su interpretación y análisis, donde se advirtió dificultad para obtener la información requerida por parte de la mayoría de empresarios.

\subsection{Resultados para transferir el ahorro privado a las empresas consensuadas}

¿Qué es una empresa consensuada (EC)? es una organización atípica empresarial, es un acuerdo formal entre varios intervinientes (Estado, inversionista, universidad, banca, comerciantes y agentes externos) para juntos entregar recursos y generar acciones que permitan obtener mejores resultados económico-político-sociales, donde un empresario provee su ahorro para invertir en una asociación con el Estado y la participación de las universidades, que funciona con reglas sinérgicas, que organizan mejor los recursos, generan mayores derivaciones y empleo, en base a proyectos innovadores y técnicos, y permiten, a la vez, diversificar la producción que conduce al desarrollo.

Una primera forma de estabilizar una EC, es organizar debidamente sociedades populares, comunitarias rurales o urbanas, que fomenten la producción y motiven el empleo, potencien a los integrantes de la economía popular y rural, mediante la elaboración y entrega de proyectos productivos por parte de las universidades y entes dedicados a esta labor, que permita disponer de proyectos con financiamiento rápido y barato, conforme firma de convenios o negociación con la Banca, por ejemplo, trocar su financiamiento al Bono de Desarrollo Humano, por líneas de crédito popular, con intereses básicos, que oscilen entre el 5 y el $7 \%$, constituyéndose en el segmento más barato y popular del crédito bancario, el microcrédito, que hoy es el más caro, aplicando reglas ciertas y seguras para las partes, de tal modo que, cada crédito concedido tenga la convicción de su retorno, lo cual propende a la masificación bancaria en este segmento popular (más clientes, más ganancias en escala), es una forma de concertar, sin regalos ni donaciones, ni redistribuciones obligadas, esto se consigue mediante lo siguiente:

Cada empresa consensuada, tiene que constituirse con la obligación de producir en comunidades rurales o urbanas productivas, por ejemplo, una zona o sector conformado por varios campesinos, debe comprometerse el hacer producir sus tierras con determinado producto, apto para su localidad, donde, en lo posible, todos los vecinos provean sus tierras para juntos producir masivamente un producto, por ejemplo, brócoli, trigo, etc. (vecino que no se integra, tendrá plazo, si no se le arrienda para integrarlo a la producción por igual), que les permita acopiar en silos su vasta producción, y que a la vez, agreguen valor, esto es, transferir tecnología al campo o al sector popular para semi industrializar sus 
productos, que se destinarán a extensos mercados nacionales o externos.

Para ello, el Estado resulta clave constituirse o asumir el rol de coordinador y líder de esta labor, primero, dotando de asesores, administradores o técnicos senior para esta tarea específica, donde también se incorporan los proyectos y estudiantes (o neo-profesionales) de las universidades (diversas carreras), específicamente capacitados, alineados a requisitos y perfiles, quienes deberán luego tomar el relevo de dicho consultivo senior, de tal modo que, se transfiera y popularice la tecnología productiva, esto es, transponer tecnología de punta hacia sectores populares desordenados e improductivos, que una vez organizados, produzcan eficientemente en grupos bien constituidos, que se normarán conforme concertación, tanto en aspectos técnicos, sanitarios, legales, etc.

El Estado debe asumir el rol de manager, de gestión, de enlazar mercados para esta producción consensuada, sea con empresarios o gobiernos, para alcanzar su compromiso y convenir el acceso a nuevos mercados, sean locales o externos, conforme acuerdos mutuos entre empresarios, distribuidores y regímenes, así como el de dotar de proyectos productivos populares en convenios con universidades, de consultivos seniors, facilitar la constitución de estas empresas y conseguir la tecnología requerida para el efecto. De este modo, se estimula y fomenta el empleo, la universidad se integra a la producción con la colocación de sus neo-profesionales o pasantes al proceso de producción y al desarrollo nacional, el Estado asume un rol de adalid, no solo de recaudador o regulador coercitivo, sino de motivador e impulsor de este proceso, que genere confianza y seguridad en sus gestiones, dinamizando la conducción de recursos hacia la producción, ya sea de la banca, como de potenciales inversionistas locales o externos, conforme estándar propuesto.

Otra forma de EC se integra cuando se motiva directamente la disposición del ahorro privado para este tipo de inversión compartida, al contar con un proyecto productivo diversificado (que conciba mayor producción y mercados nacionales o externos) para pequeños y medianos empresarios (en una segunda etapa para grandes), que comprueben su funcionalidad y certeza de este tipo de procesos, que son verdaderas asociaciones público-privadas ya que, en estas empresas concertadas, donde la producción se diversifica en razón de que el gobierno, agenciará procesos masivos en amplios mercados para colocar estos productos con agregación de valor, donde las nuevas reglas empresariales son beneficiosas para sus actores, por cuanto de aplica el criterio de economías de escala, integrar más recursos, producir más, vender a mejores precios y ganar más, así el porcentaje de utilidad sea inferior.

En este sentido, se destierra el criterio atávico de que el sector privado es solo subsidiario, cuestiona el andamiaje constitucional-jurídico ecuatoriano, que privilegia lo público en desmedro del interés privado, que rompe el sembrado criterio de un Estado omnipotente y omnipresente, que echa por tierra el tradicional divorcio del sector público y del privado, que rompe el paralelismo de intereses aislados que tiene cada sector, sino más bien, que los integra fácilmente, con respeto de su rol definido, dinámico, eficiente y creciente de resultados productivos, así, la empresa privada, que ha entregado su ahorro para ser invertido, asume nuevas reglas de funcionamiento, ya que su inversión, que siempre será privada, debe ser manejada por el gestor público para la concertación, con nueva normativa, con trabajadores y administradores asignados por el gestor, cuyo directorio se integra con técnicos públicos y privados (caso universidad e inversionista), de este modo, el funcionamiento, producción y mercadeo queda a cargo de un Comité de APP consensuado, seguido de un Estado gestionador, veraz y confiable, que genere certezas para que otros empresarios o inversionistas se sumen o emulen este proceso.

Las utilidades generadas, deberán optar por nuevas reglas, esto es, compartir entre los trabajadores y el Estado mejores porcentajes de repartición, para el efecto debe cambiarse la ley del $15 \%$, de tal modo que, al ser una empresa eficiente, diversa y de amplia proyección, los resultados siempre serán mayores que si invertiría por sí solo, a lo tradicional, a esto es lo que se llamará la utilidad sinérgica, donde el inversionista gana más que de la forma tradicional, debido a que su producción es diversificada, social y el mercado es mayor, dispone de mejor tecnología, con la integración de nuevos actores concertados que amplifican el proceso productivo, lo cual, justifica el empeño conjunto de estos mecanismos, que hasta ahora, se encuentran tiernos o aislados.

Las alianzas público-privadas (APP) tradicionales, o empresas mixtas, se pueden figurar como si fueran matrimonios arreglados, en donde los cónyuges solo se reúnen para obtener algún objetivo que buscan, con una especie de predominio de género del Estado sobre su par privada, que se impone por su magnitud coercitiva, uniones de derecho que, usualmente, han sido acordadas para realizar solo obras infraestructurales, pero sin una verdadera fusión o alineación, que cumplido su objetivo se desintegran. La propuesta es centrípeta integra lo aislado, conjunta la capacidad productiva del país, sinergiza y centra recursos, maximiza el empleo, integra sectores, amplía la producción y conduce al desarrollo.

Para el efecto se ha consultado a un importante número de empresarios privados del este sector austral del país, que han manifestado sus puntos de vista referentes a varios criterios al respecto de consignar alianzas público-privados, conforme sigue: Ante la pregunta de si consideraría la posibilidad de invertir en nuevos proyectos empresariales productivos, se obtiene que, del total de los empresarios encuestados, el $45 \%$ si consideran la posibilidad de invertir en nuevos proyectos empresariales productivos, denotando un espíritu empresarial, sin embargo, el $50 \%$ de la población no responde, debido al desinterés por invertir; y, el $5 \%$ de los encuestados no desean invertir en nuevos proyectos, conforme se visualiza en la figura 2: 
Figura 2.

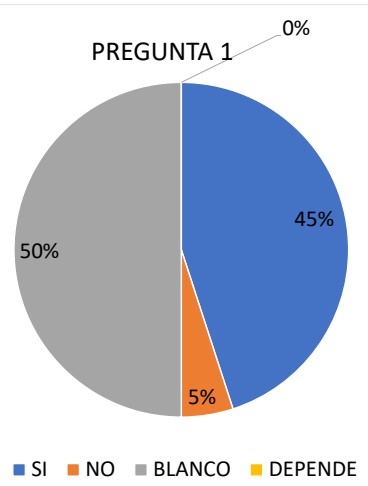

Fuente y elaboración: Autores

Figura 3 .

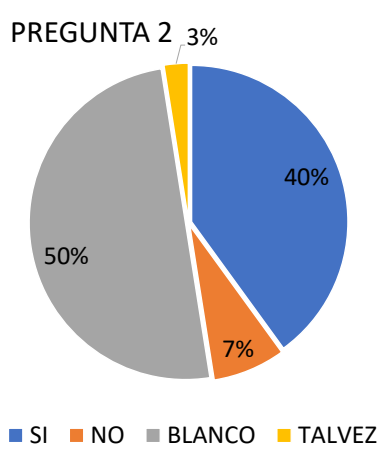

Fuente y elaboración: Autores

La consulta sobre si en caso de invertir en un proyecto productivo, estaría dispuesto en compartirlo con el Estado, el $40 \%$ sí está dispuesto a compartirlo, de este porcentaje, el $10 \%$ si confía en el Estado; el 7,5\% considera que el Estado ayudaría de forma sustancial en este propósito; el $2,5 \%$ razona que el mercado se ampliaría para sus productos, o que también permitirían compartir proyectos productivos, si les resultan éstos gratis; el $15 \%$ piensa que es una inversión más segura con el Estado; el 2,5\% reflexiona que el Estado es una entidad que tiene mayores proyecciones, que tiene criterio de solidaridad con los demás; y, estima que al invertir tendría seguridad en su patrimonio. Según la Gráfica 2, el $7 \%$ del total de entrevistados no está dispuesto a compartir un proyecto productivo con el Estado, pues, consideran que es decisión privada el invertir por su cuenta. El $50 \%$ no tiene ningún interés por invertir; y, solo el $3 \%$ talvez compartiría un proyecto productivo con el Estado, lo cual confirma la desconfianza existente sobre el Estado en este sentido.

Consultados si en caso de que esté seguro que su inversión con el Estado es confiable, ¿se decidiría a realizarla en seguida?, el $47 \%$ de los encuestados si decidiría realizar la inversión en seguida; no obstante, el $50 \%$ no contesta porque a pesar de su decisión afirmativa, prefiere pensarlo bien; y, el $3 \%$ señala que dependería de un análisis del proyecto a compartir (Figura 4):

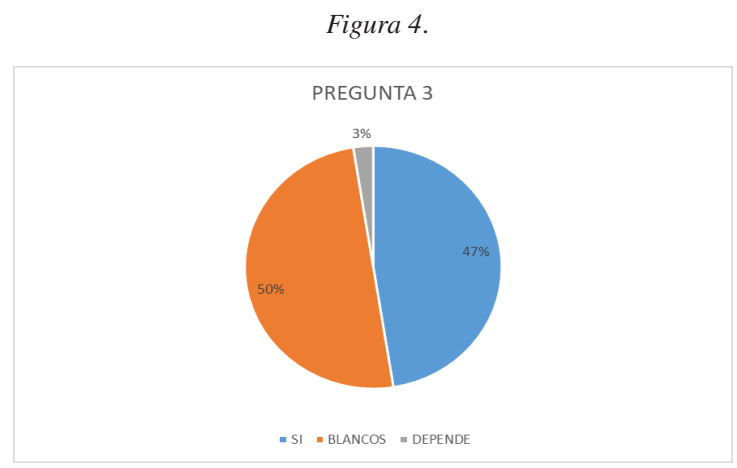

Fuente y elaboración: Autores

Figura 5.

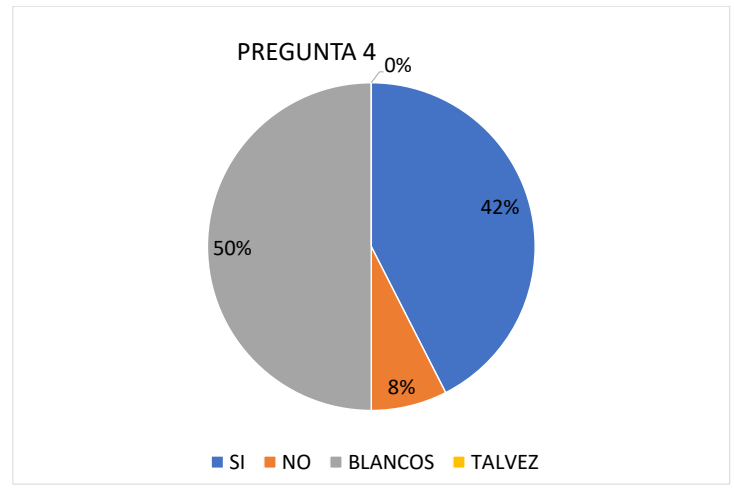

Fuente y elaboración: Autores

En la figura 5 se encuentran las respuestas a la pregunta que, si en base a la afirmación de que estaría de acuerdo a su inversión con el Estado en proyectos productivos, ¿permitiría compartir o permitir decisiones?, el $42 \%$ de los encuestados estaría de acuerdo que su inversión sea bajo el criterio de compartir o permitir decisiones estatales; el $50 \%$ de los encuestados prefiere no opinar; solo el $8 \%$ dice que no estaría de acuerdo en este criterio ya que se escaparía decidir sobre lo suyo. Aquí se abre una oportunidad.

Consultados si tendría algún reparo si su inversión compartida se destinaria al beneficio social o popular, solo el $2 \%$ del total de encuestados señala que sí tendría reparos si su inversión compartida se destinaria al beneficio social o popular, siendo un porcentaje de baja incidencia; el $33 \%$ señala que depende si no afecta a sus intereses económicos, lo que significa que las reglas de juego deberían estar muy claras y seguras; el $50 \%$ aún no decide sobre esta posibilidad, seguramente por su incertidumbre flotante; y, el $15 \%$ no tendría algún reparo si una inversión compartida se destinaria al beneficio social o popular, aspectos que demuestran, en su conjunto, existe alta desconfianza por las decisiones del Estado en intereses privados, a pesar de su 
decisión de compartir, aspecto que confirma la oportunidad de integrar estas empresas concertadas (ver figura 6):

Figura 6.

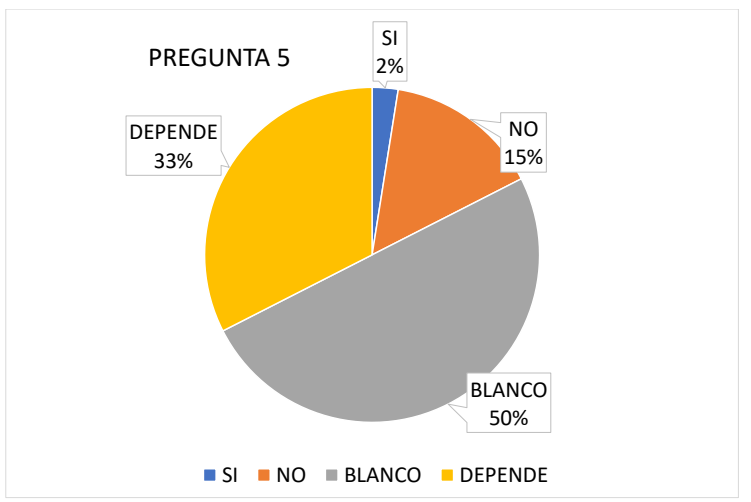

Fuente y elaboración: Autores

Figura 7.

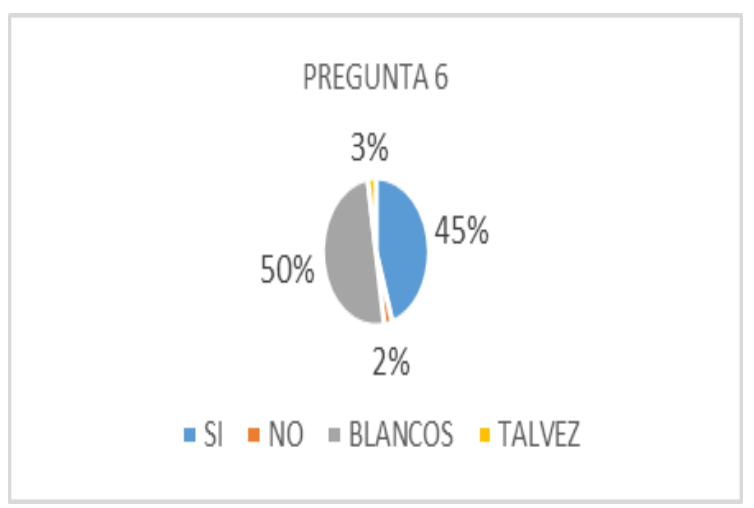

Fuente y elaboración: Autores

La pregunta de la figura 7 , de que si ha aceptado en invertir conjuntamente con el Estado en proyectos factibles y productivos ¿estaría de acuerdo en reducir el porcentaje de su utilidad en beneficio del Estado o comunidad a cambio de mayores ingresos y resultados económicos?, el $45 \%$ responde que sí estaría de acuerdo en este prospecto, lo cual visualiza que existe un gran porcentaje de decisión de cambio, siempre que sea un ganar-ganar; el $3 \%$ no estaría de acuerdo; el $50 \%$ prefiere no responder todavía; el $2 \%$ señala que talvez, respuestas que mantienen un similar patrón de conducta a su criterio sobre la inversión compartida.

En la cuestión de que, una vez aceptada la asociación, ¿permitiría que sea el Estado quien provea el proyecto, las personas y la gestión del mercado para esta inversión?, el $45 \%$ de los encuestados sí permitiría, expresa que es un gran apoyo a sus proyecciones; el $3 \%$ señala que talvez lo haría; el $2 \%$ no lo permitiría; manteniéndose en la mitad de los encuestados en preferir no contestar a esta pregunta, aspecto que confirma su patrón de conducta que no tienen certidumbre o claridad sobre esta nueva propuesta (figura 8).

Figura 8 .

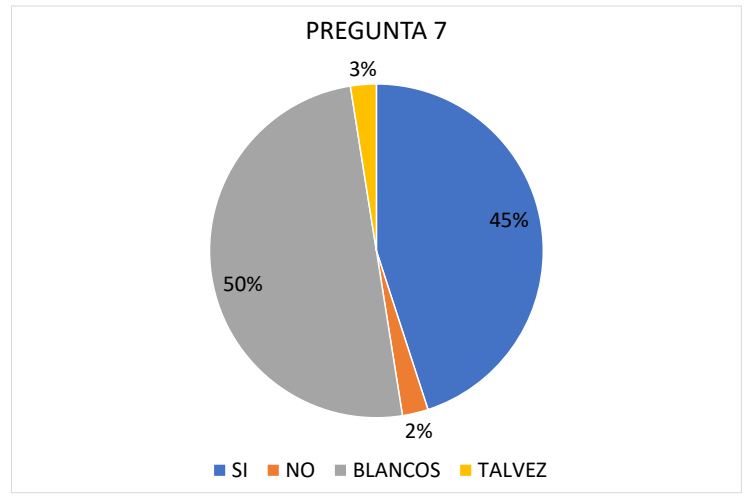

Fuente y elaboración: Autores

Figura 9 .

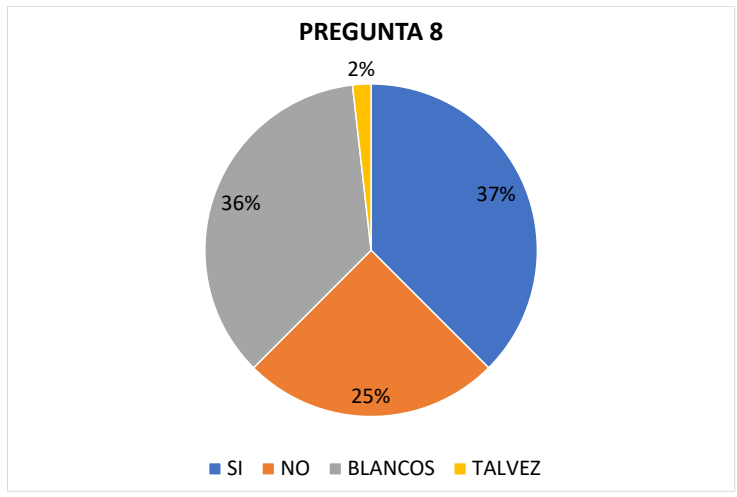

Fuente y elaboración: Autores

En la pregunta 8 (figura 9), que versa sobre si, una vez superadas todas las incertidumbres para este tipo de APP, y una vez verificado este modelo de inversión compartida funciona, se debería aplicar en los demás inversionistas, el $21 \%$ señala que sí, el $14 \%$ no, el $20 \%$ no emite criterio, el $4 \%$ dice que talvez, aspectos que por sí, dan paso a la posibilidad real de que el ahorro privado puede transferirse a estas empresas concertadas, y que, se debería replicar en el resto de empresarios, aspecto que demuestra cumplir el objetivo.

\section{Conclusiones}

El presente estudio permite alcanzar valiosas conclusiones como son:

- El objetivo general se cumple en la medida en que se han formulado procesos productivos que se consideran eficientes, si bien en principio hay rechazo a invertir con el Estado, sin embargo, tienen gran apertura para aceptar este tipo de proyectos, si se logra confianza, por ser viables, ya que una vez aplicados, aumentará 
la riqueza y el empleo, que revertirá la condición de pobreza de muchos, los inversionistas podrán ganar más con estas EC, que emprendiendo solos.

- Toda modalidad de alianza público-privada requiere de una certeza y ordenamiento jurídico adecuado, de disponer de leyes y normas que sustenten el proceso.

- El Estado deberá asumir un rol de motivador y coordinador líder del desarrollo de las EC, proveyendo de administradores senior, proyectos productivos, tecnología, mercados, leyes apropiadas y debida coordinación entre los actores.

- Con este modelo, la economía se vuelve centrípeta, ya que todas las fuerzas, recursos y capacidades productivas, operan mirando hacia un mismo centro que es el beneficio mutuo y social, con el uso óptimo de los recursos que generan sinergias productivas.

- Este mecanismo permite transmitir el ahorro a la inversión en alta magnitud, aspecto que estimula una mayor producción sistematizada (matriz de producción) y que conlleva a una tecnificación masiva de la producción (matriz productiva popular).

- Las APP tradicionales se forman para cumplir propósitos conocidos, las consensuadas para hacer diversificar resultados, incorporar empleo y optimizar recursos.

- Se requiere un alto grado de compromiso del Estado, que asuma un rol integrador, de liderazgo, gestionador y concertador, en forma técnica, eficiente y perseverante, y un compromiso igual, complementario y perdurable del resto de actores.

- Muchos empresarios, en principio, tienen desconfianza con el Estado para compartir alianzas de inversión conjunta, existe incertidumbre, pero este criterio se advierte que puede ser revertido si se demuestra su efectividad y se vuelva cierto y confiable.

- Los empresarios aceptarían participar en empresas de beneficio social y popular, siempre que sus intereses no se vean menoscabados, incluso muchos aceptan reducir la participación porcentual de las utilidades, siempre que, a la larga, ganen más.

- Queda claro que, el sector público y privado, tradicionalmente apartados, pueden complementarse exitosamente, compartir verdaderas coincidencias, si todos obtienen beneficios, se mantienen sus derechos privados y a la vez se desarrollan juntos.

\section{Recomendaciones}

- Instituir el presente modelo de empresas concertadas, por ser beneficioso para todos.

- Alcanzar una concertación social para emprender con este tipo de proyectos de inversión, para lo cual, el Estado debe liderar el proceso y garantizar, al menos en las etapas iniciales, el cuidado del ahorro dedicado a la inversión.

- Reformar las leyes pertinentes, para que se crean de forma normativa este tipo de emprendimientos, como es el caso del incremento del $15 \%$ de utilidades para los trabajadores, el abaratamiento del crédito popular por parte de la Banca, y el compromiso regulado del Estado para ser gestor y garante de estos procesos.

- Elaborar un modelo económico centrípeto, de tal manera que se estimule la participación de todos los empresarios con este tipo de emprendimientos bien organizados, para que, se aproveche al máximo la capacidad productiva potencial.

- Estimular y desarrollar primero la producción masiva, para en forma paralela, desarrollar una matriz productiva popular.

- Demostrar con prototipos la vialidad de este proceso, sus alcances y formalidades productivas, a fin de que se genere credibilidad, certeza, con un efecto multiplicador.

- Conforme la investigación, los empresarios o ahorristas, pueden integrarse a estos procesos y recomendarlos, una vez certifiquen su convicción y mayores beneficios, para lo cual el Estado debe generar certidumbres, confianza, base legal coherente, seguridad en la inversión y garantías para conciliar procesos concertados y solidarios.

- Se debe desmitificar la discordancia de intereses del Estado con los de la sociedad civil, si se concilian acuerdos de mutuo beneficio, y se acepta que el proceso es posible, debido a su consistencia operativa y a la garantía de mejores resultados.

- Al existir cierta debilidad en el estudio, debido a la dificultad de obtener suficiente información por parte de los empresarios, se sugiere continuar con más indagaciones.

- Existen muchos estudios sobre las APP, con su casi total criterio de participar con la sociedad civil en concesiones de obras infraestructurales o empresas mixtas, sin una verdadera concertación social, con prevalencia de intereses del Estado, por lo que, es importante balancear los aportes de todos los sectores y agentes participantes.

\section{Referencias Bibliográficas}

Asamblea Nacional. (2010). Código Orgánico de Organización Territorial, Autonomía y Descentralización. Registro Oficial No. 303, del 19 de octubre de 2010, Título V, capítulo IV, artículo 129.

Asamblea Nacional. (2014). Ley de Compañías. Registro Oficial No. 312, de 5 noviembre de 1999, con reforma del 12 de septiembre de 2014 ..

Asamblea Nacional. (2015a). COIPE. Registro Oficial. No. 351, de 2010, con reforma del 18 de diciembre de 2015.

Asamblea Nacional. (2015b). Constitución de la República del Ecuador. Registro Oficial 449 del 20 de octubre de 2008, con reforma del 21 de diciembre de 2015. .

Asamblea Nacional. (2015c). Ley Orgánica de Empresas Públicas. Registro Oficial No. 48, del 16 de octubre de 2009, con reforma del 18 de diciembre de 2015. 
Baldeón Barriga, M. I. (2016). Las asociaciones público privadas (APP) en el marco jurídico ecuatoriano. $F O$ RO, Revista de Derecho No 25, UASB-Ecuador/CEN. Quito, 119.

Baldeon Barriga, María. (2016). Las asociaciones público privadas (APP) en el marco jurídico ecuatoriano. Seminario Taller de Runachay Rantiy Cia. Ltda., empresa del grupo CEAS, 2016-01-29, Quito, 121.

Banco Mundial. (2018). Banco Mundial BIRF - AIF DOING BUSINESS. Descargado de http: / / espanol.doingbusiness.org/ $\{\sim\} /$ media/WBG/DoingBusiness/ Documents/Annual-Reports/English/ DB2018-Full-Report.pdf .

CEPAL. (2016). Estudio Económico de América Latina y el Caribe, 2016. Descargado de https://repositorio.cepal.org/ bitstream/handle/11362/40326/91/ 1600548EE_Ecuador_es.pdf

Cámara de Comercio de Guayaquil.

(2018a) http://www.lacamara.org/website/wpcontent/uploads/2017/03/APE-023-Ahorro-e-Invers. Descargado de http://www. lacamara.org/ website/wp-content/uploads/2017/03/ APE-023-Ahorro-e-Invers

Cámara de Comercio de Guayaquil.

(2018b). http://www.lacamara.org/website/wpcontent/uploads/2017/03/APE-023-Ahorro-eInversi \%C3\%B3n-en-Ecuador.pdf. Descargado de http://www.lacamara.org/website/ wp-content/uploads/2017/03/APE-023 -Ahorro-e-Inversión-en-Ecuador.pdf

Congreso Nacional. (1993). Ley de Modernización del Estado, Privatización y Prestación de Servicios Públicos. Registro Oficial No. 349, de 31 de diciembre de 1993, artículo 1, literal c.

Diario Las Américas. (2018). Diario Las Américas. Descargado de https:// www.diariolasamericas.com/ america-latina/radiografia-los -paises-latinoamericanos-el-indice -corrupcion-n4144148

El Comercio. (2018). Deuda pública de ecuador asciende a usd 58980 millones. Descargado de https://www.elcomercio.com/ actualidad/deuda-ecuador-finanzas -coplafip-loreytf.html

Enriquez, I. (2009). La construcción social de las teorías del desarrollo. México: Miguel ángel Porrúa, 1 ed.

France 24. (2018). France 24. Descargado de https://www.france24.com/es/ 20180222-indice-corrupcion-america - latina-transparencia

Francois, B. (2016). Le Parteriatiat Public-Privé, Presupuesto y Gasto Público. Instituto de Estudios Fiscales. FORO, 24.
Inteligencia Productiva. (2018). Evolución de establecimientos, Gráfico 14 . con fuente SRI, año 2016. Descargado de http:// wWw. inteligenciaproductiva.gob.ec/ cifras

Invenómica. (2018). Riesgo País EMBI - América. Descargado de https://www.invenomica .com.ar/riesgo-pais-embi-america -latina-serie-historica/

Krugman Obstfeld, M., y Mélitz, M. R. (2016). Economía Internacional, Teoría y Política. Madrid: Pearson Educación S.A.

La República. (2018). LR La República. Descargado de https://www.larepublica.co/ globoeconomia/chile-peru-y-uruguay -tienen-el-menor-riesgo-pais-en-el -indice-de-ip-morgan-2593400

LOAIAPP. (2015). Ley Orgánica de Incentivos para las Asociaciones Público Privadas y la Inversión Extranjera. R.O. No. 652 del 18 de diciembre de 2015.

Molina, M. (2016). El contrato de colaboración entre el sector público y el sector privado en España. FORO, 24.

Pacheco, L. (2009). Política Económica. Quito: Gráficas Iberia, 3ra. Ed.

Presidencia de la República. (2015). Reglamento de Régimen de Colaboración Público Privado, Boletín No. 453. Descargado de https://v/ lex.ec/expidece-reglamento-regimen -colaboracion-569013690

Robalino Orellana, J. (2011). FORO Revista de Derecho, No. 13, UASB-Ecuador / CEN Quito, 2010. Descargado de http:// repositorio.uasb.edu.ec/bitstream/ $10644 / 5765 / 1 / 07-\mathrm{TC}-\mathrm{Baldeon}$.pdf

Samuelson, W., y Nordhaus, P. (2010). Macroeconomía con aplicaciones a Latinoamérica, 19ed. México: McGraw-Hill.

Vieitez y col. (2016). Módulo 1 del Diplomado en asociaciones público privadas para el desarrollo de infraestructura y servicios. . FORO, 24.

Recibido: 30 de junio de 2018 Aceptado: 3 de septiembre de 2018 